\title{
Impact of Annealing Temperature on Structural, Morphological, Photoconductivity of Aluminum Doped Zinc Oxide (AZO) Nanorods Prepared by Microwave Assisted Precipitation Method
}

\author{
P. Ramesh Kumar*, V. Balaprakash and P. Gowrisankar \\ Department of Electronics, Hindusthan College of Arts and Science, Coimbatore - 641028, Tamil Nadu, India; \\ rameshprabha.ps@gmail.com, km.balaprakash@gmail.com, pgsankar3@rediffmail.com
}

\begin{abstract}
Objectives: The AZO nanoparticles are prepared by novel microwave assisted precipitation method with varying annealing temperature. Methods/Findings: The research work explores preparation and Structural, Morphological and Photoconductivity investigations of aluminum doped Zinc oxide (AZO) nanoparticles. Structural, Morphological and Optical Characteristics are examined by X-Ray Diffraction (XRD), Scanning Electron Microscope (SEM) and UV Visible Spectroscopy (UV-Vis) respectively. The XRD analysis reveals that the crystallite size was $42.3 \mathrm{~nm}, 45.2 \mathrm{~nm}$ and $50.7 \mathrm{~nm}$ for the annealing temperatures of $450^{\circ} \mathrm{C}, 600{ }^{\circ} \mathrm{C}$ and $750{ }^{\circ} \mathrm{C}$. The shape of the nanoparticles observed in hexagonal wurzite format. The maximum level of peaks is observed in (100), (002), (101), (102), (110), (103), (200), (112), (201), (004) and (202) planes for various annealing temperatures. The SEM image indicates that the morphology has rod shape structure. The optical absorbance spectra of AZO nanoparticles were about $384.00 \mathrm{~nm}$. The FTIR spectra shows the presence of aluminum content in the synthesized nanoparticles. Applications: The prepared AZO nanoparticles can be applied to prepare the gas sensors.
\end{abstract}

Keywords: Nanorods, AZO, EDAX, SEM, FTIR, XRD

\section{Introduction}

$\mathrm{ZnO}$ is an $\mathrm{N}$ type semiconductor having direct energy band gap $(3.37 \mathrm{eV})$ and high binding energy $(60 \mathrm{meV}) \stackrel{1}{\text {. }}$ $\mathrm{ZnO}$ nanoparticles can be used in sensors, catalysis, water purification, antibacterial, nano electronics, solar energy, cosmetics, paints, synthetic textiles, food packaging, medical care, healthcare, tooth paste, detergent and sun screen. At room temperature the electrical resistivity of the Zinc oxide was in the order of $0.75 \mathrm{M} \Omega$. The resistivity of the $\mathrm{ZnO}$ material can be reduced by doping with group - III materials. Zinc oxide materials can be easily doped with group - III material such as Ga, In, $B$ and $A^{!}$. In this work, aluminum is doped with $\mathrm{ZnO}$ nanoparticles. $\mathrm{AZO}$ is a valuable alternative to ITO materials. It has increased optical transmittance and low electrical resistance ${ }^{2}$.

Synthesized AZO nanoparticles can be prepared by sol gel, spray pyrolysis, precipitation, hydrothermal method, chemical vapor deposition and microwave irradiation. Extensively the microwave irradiation method is used to synthesize the AZO nanoparticles. Microwave irradiation method draws all notice owing to its homogeneous volumetric heating, simple and economical method ${ }^{3,4}$ The prepared AZO nanoparticles having peculiar optical property and also it has predominant application in electric transducer, solar cell and gas sensors ${ }^{5,6}$. 


\section{Experimental Section}

Figure 1 shows the synthesized producer of AZO nanoparticles for different annealing temperature. In this synthesized method the aqueous solution of Zinc acetate dihydrate. $\left(\mathrm{Zn}\left(\mathrm{CH}_{3} \mathrm{COO}\right)_{2} 2 \mathrm{H}_{2} \mathrm{O}\right)$ is an precursor and Aluminum nitrate nano hydrate $\left(\mathrm{Al}\left(\mathrm{NO}_{3}\right)_{3} 9 \mathrm{H}_{2} \mathrm{O}\right)$ was a source of aluminum. 1.0 M of Zinc acetate dihydrate was dissolved in $100 \mathrm{ml}$ of double distilled water by using hot plate magnetic stirrer. 1 at \% of aluminum nitrate nano hydrate was mixed with this dissolved solution. Liquid ammonia also added in to it drop wise to adjust the $\mathrm{Ph}$ value to 8.0. The mixed solution was stirred vigorously for $40 \mathrm{~min}$ at $80{ }^{\circ} \mathrm{C}$. The prepared solution was allowed to get cool at room temperature. At last white colored AZO precipitate formed at the bottom of the beaker. The same method was followed to prepare two more aluminum doped zinc oxide nanoparticles with same molar concentration.

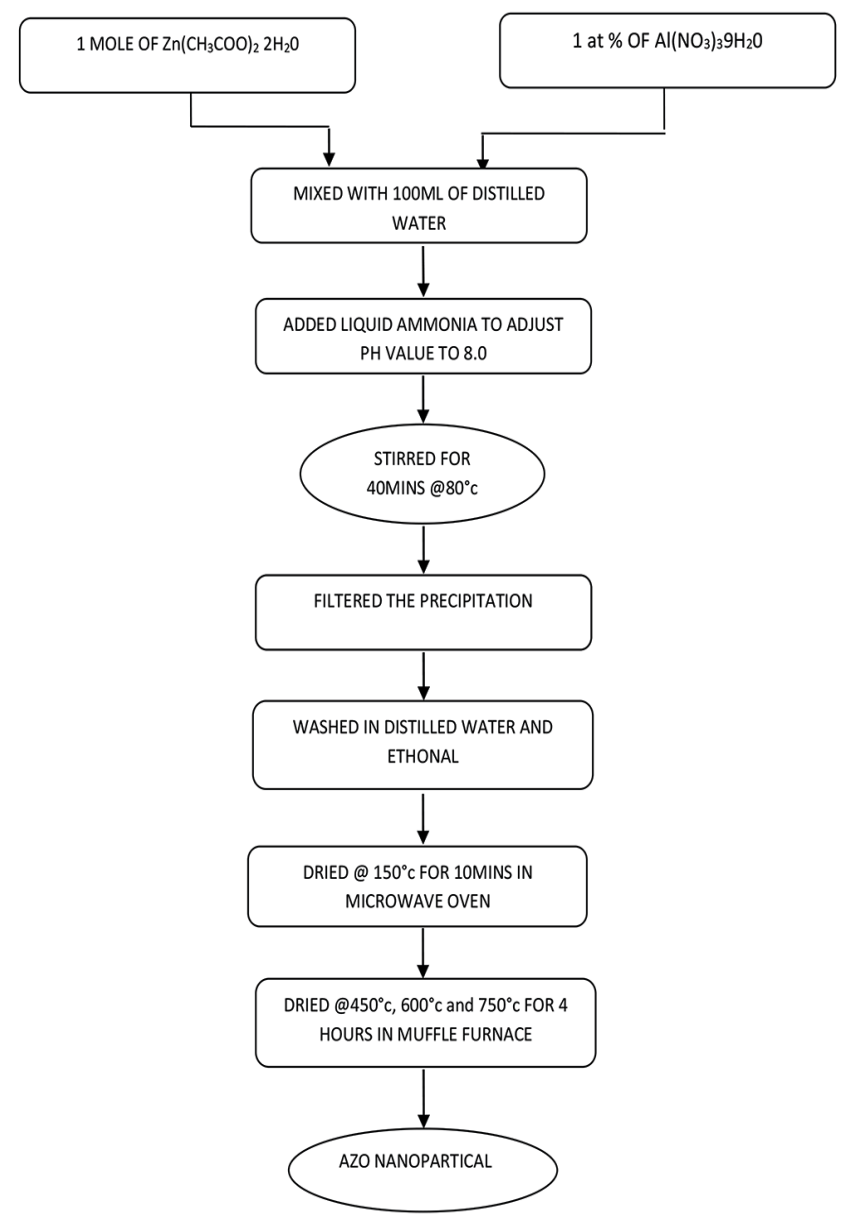

Figure 1. The preparation of AZO nanoparticles.
All three white colored prepared precipitates were filtered separately using whatman filter paper and was washed for four times using double distilled water and ethanol. The washed precipitates were dried using microwave oven to evaporate water molecules. The microwave irradiation was performed in convection method for $10 \mathrm{~min}$ at $150{ }^{\circ} \mathrm{C}$. Moreover, it was placed in muffle furnace for 4 hours at $450{ }^{\circ} \mathrm{C}, 600{ }^{\circ} \mathrm{C}$ and $700{ }^{\circ} \mathrm{C}$ to dry the synthesized nano particles again. The dried synthesized nanoparticles have been powered using mortar and pestle.

\section{Results and Discussion}

\subsection{Structural Analysis}

The structural analysis of 1 at \% of synthesized AZO nanoparticles for different annealing temperature were examined in X-RD pattern (XPERT- PRO, 30mA, 40kV) with range from 20-80 degree. Figures $2(\mathrm{a}),(\mathrm{b})$ and (c) shows the XRD pattern of synthesized AZO nanoparticles. we found that the maximum peaks at (100), (002), (101), (102), (110), (103), (200), (112), (201), (004) and (202) for $450^{\circ} \mathrm{C}, 600^{\circ} \mathrm{C}$ and $700^{\circ} \mathrm{C}$ which were matched with [Card no : 36 - 1451] of AZO material. Among these intense peaks appeared at (101) for all the annealing temperatures. It shows that the synthesized AZO nanoparticles were in hexagonal wurtzite structure also perfect orientation. The average size of the synthesized nanoparticles is calculated by Scherrer formula. The XRD analysis reveals that the crystallite size was $42.3 \mathrm{~nm}$ for $4500^{\circ} \mathrm{C}, 45.2 \mathrm{~nm}$ for $600{ }^{\circ} \mathrm{C}$ and $50.7 \mathrm{~nm}$ for $750{ }^{\circ} \mathrm{C}$.

$\mathrm{D}=\mathrm{K} \lambda / \beta \operatorname{Cos} \theta$

where $\mathrm{D}$ is the crystalline size of AZO nano particle

$\lambda$ represent the wavelength of $\mathrm{x}$-ray source $0.1541 \mathrm{~nm}$ used in XRD

$\beta$ is the full width at half maximum of the diffraction peaks

$\mathrm{K}$ is the Scherrer constant with a value from 0.9 to 1 and $\theta$ is the Bragg angle

\subsection{Morphological Analysis}

The morphology and chemical composition of synthesized nanoparticles has been studied by using Scanning Electron Microscope. Figures 3 (a), (b) and (c) shows the morphological structure of synthesized AZO nanoparticles. From the SEM analysis morphology of 


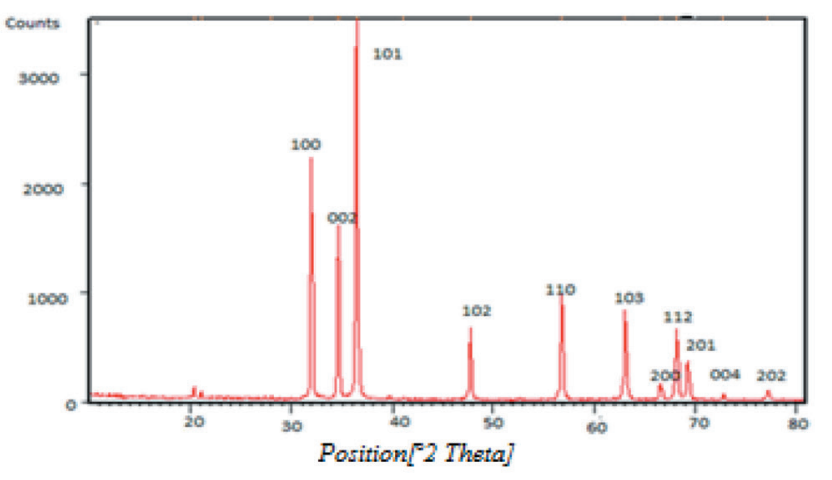

(a)

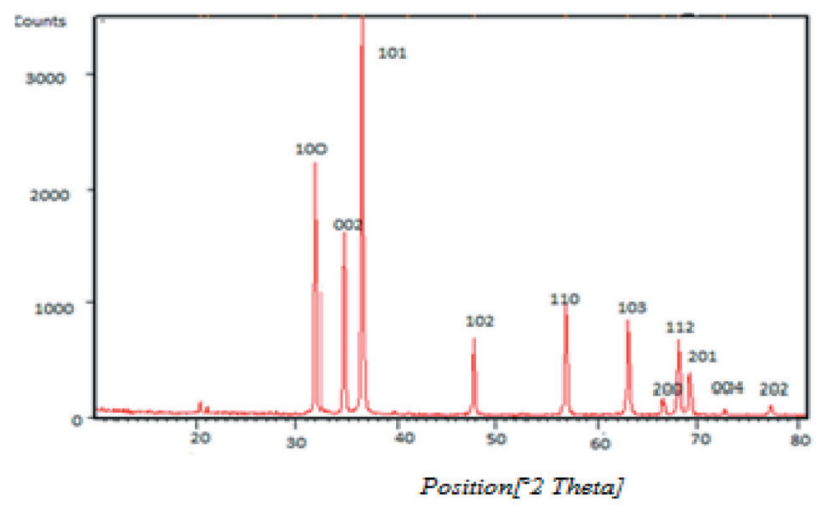

(b)

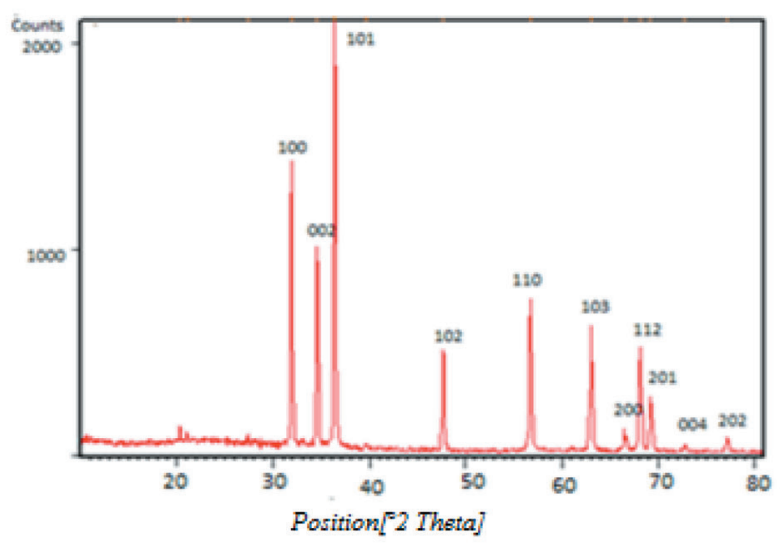

Figure 2. (a) X-RD Pattern of 1 at $\%$ of $A Z O$ nanoparticle for $450{ }^{\circ} \mathrm{C}$, (b) X-RD Pattern of 1 at $\%$ of AZO nanoparticle for $600{ }^{\circ} \mathrm{C}$, (c) X-RD Pattern of 1 at $\%$ of AZO nanoparticle or $750{ }^{\circ} \mathrm{C}$.

synthesized nanoparticles were rod shape. At $450{ }^{\circ} \mathrm{C}$, the nanorods were more agglomerated. But at $600{ }^{\circ} \mathrm{C}$ and $750{ }^{\circ} \mathrm{C}$, the synthesized nanorods were separated with each other. Clear nanorods appeared when the annealing temperature increased. Figure 4 shows the EDAX spectra of 1 at \% AZO nanoparticles for $600^{\circ} \mathrm{C}$. It confirms that the synthesized nanoparticles contain $\mathrm{Zn}, \mathrm{O}, \mathrm{Al}$ and no other impurities.

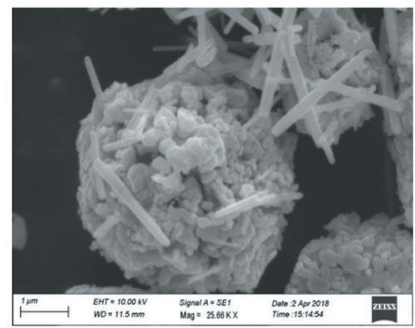

(a)

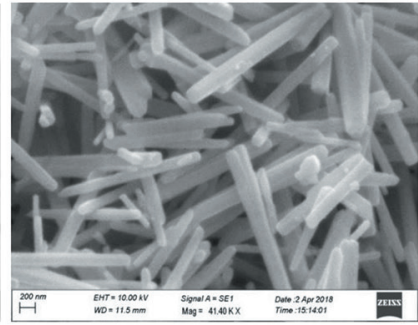

(b)

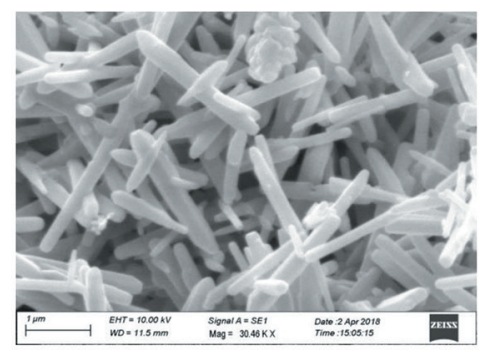

(c)

Figure 3. (a) SEM image of 1 at $\%$ of AZO for $450{ }^{\circ} \mathrm{C}$, (b) SEM image of 1 at $\%$ of AZO for $600{ }^{\circ} \mathrm{C}$, (c) SEM image of 1 at $\%$ of AZO for $750^{\circ} \mathrm{C}$.

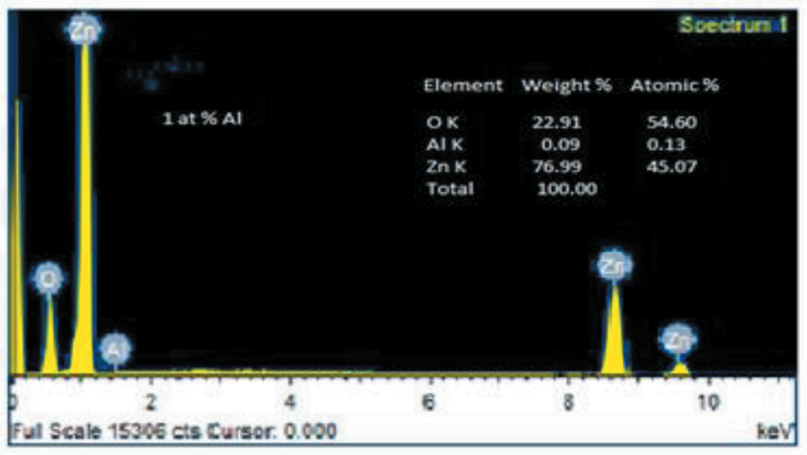

Figure 4. EDAX Spectra of 1 at $\%$ of $\mathrm{AZO}$ for $600^{\circ} \mathrm{C}$.

\subsection{UV-Vis Absorption Technique}

Figure 5 shows the optical absorbance spectra of synthesized AZO nanorods. The optical absorbance spectra of 1 at \% of Aluminum doped $\mathrm{ZnO}$ for annealing temperature $600{ }^{\circ} \mathrm{C}$ analyzed by UV-Vis spectrometer in the wave length range from $200-800 \mathrm{~nm}$. The maximum peak found at $384.00 \mathrm{~nm}$. 


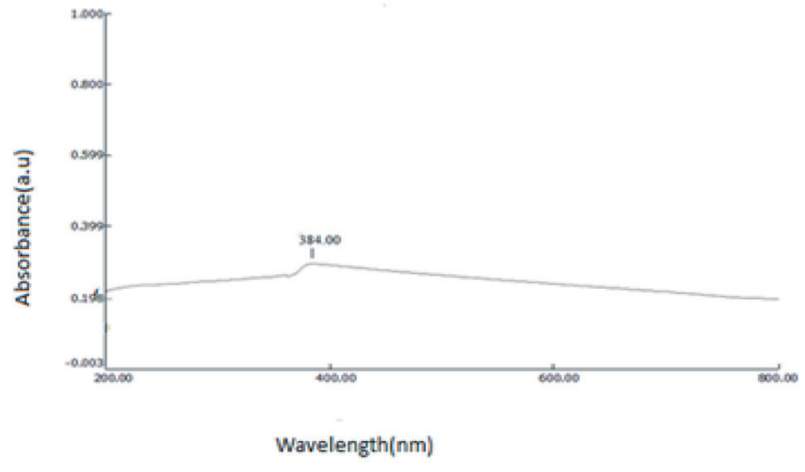

Figure 5. UV-Vis Spectra of 1 at $\%$ of $\mathrm{AZO}$ for $600^{\circ} \mathrm{C}$.

\subsection{FTIR Analysis}

Fourier Transform Infra Red Spectra reveals the chemical property of the synthesized nanoparticless. Figure 6 shows the FTIR spectra of 1 at $\%$ of AZO for $600{ }^{\circ} \mathrm{C}$. The FTIR spectra were recorded from 500 to $4000 \mathrm{~cm}^{-1}$. The absorbance peaks at $560 \mathrm{~cm}^{-1}$ and $860 \mathrm{~cm}^{-1}$ represents the presence of Al. The peak at $1500 \mathrm{~cm}^{-1}$ corresponds to $\mathrm{C}=\mathrm{O}$ groups. The peaks about $2400 \mathrm{~cm}^{-1}$ corresponds to $\mathrm{C}=\mathrm{H}$ groups. The maximum peaks between $3000 \mathrm{~cm}^{-1}$ and 3500 $\mathrm{cm}^{-1}$ corresponds to hydroxyls groups.

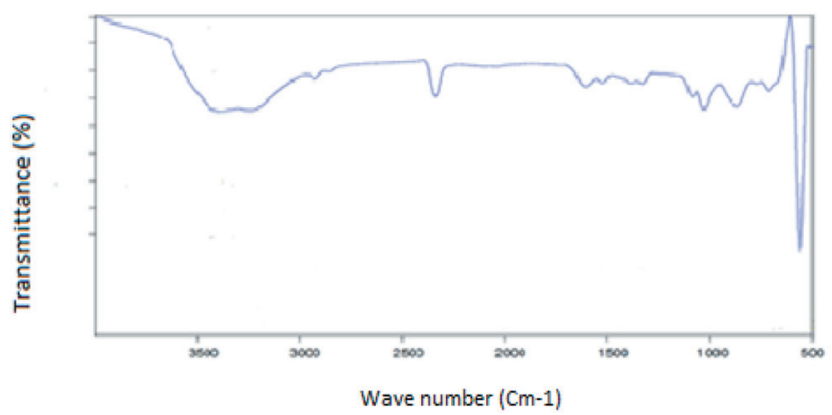

Figure 6. FTIR Spectra of 1 at $\%$ of AZO for $600{ }^{\circ} \mathrm{C}$.

\section{Conclusion}

AZO nanoparticles can be prepared by microwave assisted precipitation method. The prepared nanoparticles were analyzed by XRD, SEM, UV-Vis, EDAX and FTIR method. The synthesized nanoparticles characterized by XRD analysis shows that the synthesized particles are wurzite shape and size is $42.3 \mathrm{~nm}$ for $450{ }^{\circ} \mathrm{C}, 45.2 \mathrm{~nm}$ for $600{ }^{\circ} \mathrm{C}$ and $50.7 \mathrm{~nm}$ for $750{ }^{\circ} \mathrm{C}$. The SEM analysis shows that morphology of AZO using microwave assisted precipitation method having nonorods. The UV-Vis study also shows that absorbance spectra were $384.00 \mathrm{~nm}$. The FTIR spectra confirmed that the presence of $\mathrm{Al}, \mathrm{Zn}$ and $\mathrm{O}$ in synthesized nanoparticles.

\section{References}

1. Khan W, Khan Z, Saad AA, Shervani S, Saleem A, Naqvi $\mathrm{AH}$. Synthesis and characterization of $\mathrm{Al}$ doped $\mathrm{ZnO}$ nanoparticles. World Scientific. 2013; 22:630-6. https://doi. org/10.1142/S2010194513010775

2. Krishnakumar T, Jayaprakash R, Pinna N, Singh VN, Mehta BR, Phani AR. Microwave - assisted synthesis and characterization of flower shaped zinc oxide nanostructures. Materials Letters. 2009; 63:242-5. https://doi.org/10.1016/j. matlet.2008.10.008

3. Kiruthiga A, Krishnakumar T, Synthesis and characterization of microwave-assisted $\mathrm{ZnO}$ nanostructures. Chemistry Tech Research. 2015; 8(7):104-10.

4. Rai P, Song H-M, Kim Y-S, Song M-K, Oh P-R, Yoon J-M, Yu Y-T. Microwave assisted hydrothermal synthesis of single crystalline $\mathrm{ZnO}$ nanorods for gas sensor application. Materials Letters. 2012; 68:90-3. https://doi.org/10.1016/j.matlet.2011.10.029

5. Lupan O, Chow L, Shishiyanu S, Monaico E, Shishiyanu T, Sontea V, Roldan Cuenya B, Naitabdi A, Park S, Schulte A. Nanostructured zinc oxide films synthesized by successive chemical solution deposition for gas sensor applications. Materials Research Bulletin. 2009; 44:63-9. https://doi.org/10.1016/j.materresbull.2008.04.006

6. Hjiri M, El Mir L, Leonardi SG, Pistone A, Mavilia L, Neri G. Al-doped $\mathrm{ZnO}$ for highly sensitive $\mathrm{CO}$ gas sensors. Sensors and Actuators B: Chemical. 2014; 196:413-20. https://doi.org/10.1016/j.snb.2014.01.068 